\title{
Fact sheet-Measuring quality of care: A review of methodologies and indicators
}

Katherine Tumlinson

Follow this and additional works at: https://knowledgecommons.popcouncil.org/departments_sbsr-rh

Part of the Demography, Population, and Ecology Commons, Family, Life Course, and Society Commons, International Public Health Commons, Maternal and Child Health Commons, and the Women's Health Commons How does access to this work benefit you? Let us know!

\section{Recommended Citation}

"Fact sheet-Measuring quality of care: A review of methodologies and indicators." Washington, DC: Population Council, 2016. 


\section{MEASURING QUALITY OF CARE: A REVIEW OF METHODOLOGIES AND INDICATORS}

\section{BACKGROUND}

Despite successful efforts to increase financial and geographic access to family planning services (FP) in many parts of the developing world, large numbers of women with a desire to delay or limit future pregnancies are not using contraceptives. It is long hypothesized that the poor quality of FP service delivery in many resource-constrained settings may act as a barrier to greater contraceptive use. Starting in the 1980s, donors and technical assistance (TA) organizations devoted increasing resources to strengthening clinical quality and client counseling in particular, with efforts peaking over the next two decades. This period produced a proliferation of quality assurance, improvement, and performance improvement tools and research on quality of care's impact on FP client behaviors and health outcomes.

\section{DISCUSSION}

Broad support for the promotion of high quality service delivery in FP programs is rooted in 1990's publication of a formal framework outlining the essential elements of quality care in FP service delivery. This framework, developed by Judith Bruce, defines FP service delivery quality through six critical elements: choice of methods, information provided to clients, interpersonal relations, provider competence, follow up mechanisms, and appropriate range of services offered. Since its introduction in 1990, the Bruce framework has become the recognized standard for defining quality in the field of international FP. Global adoption of the framework was only a first step, however. Determining how to implement and assess the quality of services in the field posed a whole new set of challenges. The need for systematic, reliable, and relatively fast measures of quality led to the development of facility data collection instruments and indicators in many large demographic surveys in countries all around the world including Population Council's Situation Analysis, MEASURE Evaluation's Quick Investigation of Quality, DHS's Service Provision Assessment, WHO's Service Availability and Readiness Assessment, facility tools

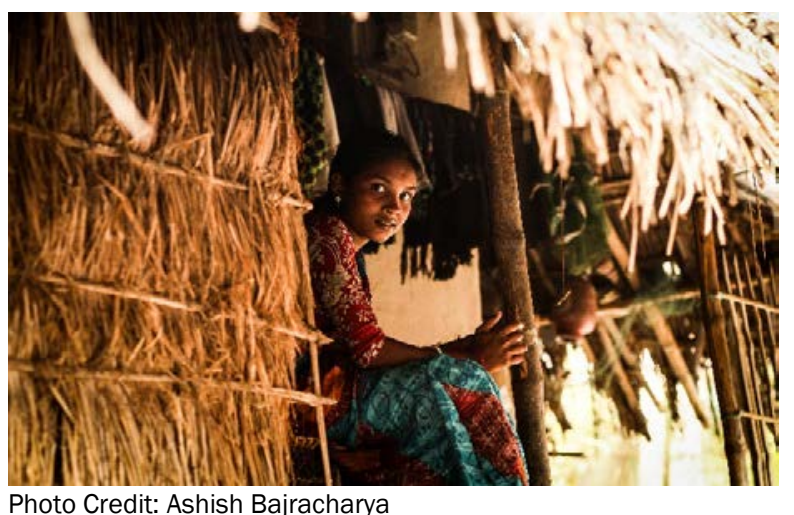

Photo Credit: Ashish Bajracharya

in UNC's Measurement, Learning and Evaluation project, and facility tools in Performance, Monitoring and Accountability 2020.

These facility surveys employ four basic data collection instruments to assess the quality of FP services: a facility audit, observation guide, and questionnaires for FP service providers and exiting clients. These tools can be used in any combination, and one or more can be omitted to reduce the financial, logistical, or time burdens of facility data collection.

Several methodological concerns exist when using standard data collection instruments, including courtesy bias, recall bias, validity of provider interviews, and social desirability bias. Another possibility is the Hawthorne effect, when providers know they are being observed and are likely to act differently than when alone with a client. There are a few possible solutions for avoiding Hawthorne bias while still observing client and provider interactions including audio- or video recording interactions for subsequent review. Another, more common, approach is the mystery or "simulated" client method whereby a woman pretending to be an actual new FP client presents at a health facility for a FP counseling session, with the provider unaware the 'client' has a research agenda. Often providers are informed that they would be visited by a "simulated client" over the next few months while unaware who this person might be or exactly when she may appear.

Many small studies select elements of quality based
The Population Council conducts research and delivers solutions that improve lives around the world. Big ideas supported by evidence: It's our model for global change. popcouncil.org
POPULATION COUNCIL

Ideas. Evidence. Impact. 
upon the feasibility of available secondary or primary data. As a result of inconsistently applied measures of quality, comparisons across geographic regions or time periods among these smaller studies is difficult. A few larger and more comprehensive studies of quality have combined specific indicators or aspects into an overall index, including how quality of care indices were calculated. The benefits and limitations of creating index or composite variables from numerous quality variables should be discussed within the FP research community, considering strategies such as principle component analysis used in the recent DHS Analytical Studies 44: Assessing the Quality of Care in Family Planning, Antenatal, and Sick Child Services in Health Facilities in Kenya, Senegal, and Namibia.

\section{CONCLUSION}

Studies investigating the quality of FP services represent a great diversity in how quality is defined and which elements of quality are considered most important. There is no agreed set of indicators for quality of care, and inconsistent definitions pose a challenge for summarizing the results of studies investigating quality of care in FP programs. Frequent use of quality indices may facilitate analysis but creates challenges for translating research results into policies and programs for quality improvement. Despite widespread endorsement of the Bruce framework and development of standardized data collection instruments, obstacles to accurate measures of quality of care remain. Furthermore, few countries collect facility data, and even fewer observe clients' interactions with their health care providers to verify data from exit and provider interviews. The simulated client method could provide additional helpful information but is not frequently used, nor has a standardized tool been developed. Further discussion within the research community must ensure appropriate, feasible, and efficient strategies for measuring quality, to reduce quality-related barriers to optimal FP use.

This brief is based on the Working Paper 2 prepared by Katherine Tumlinson for the Measuring and Monitoring Quality of Services and Quality of Care project funded by a grant from the David and Lucile Packard Foundation to the Population Council. We gratefully acknowledge the support and encouragement of the Foundation to continue research on the current state of quality of care.

\section{REFERENCES}

1. Askew, I., B. Mensch, A. Adewuyi. 1994. Indicators for measuring quality of FP services in Nigeria. Studies in FP 25(5):268-283.

2. Bessinger, R.E., J.T. Bertrand. 2001. Monitoring quality of care in FP programs: Comparison of observations and client exit interviews. Int'I FP Perspectives 27(2):63-70.

3. Brown, L. et al. 1995. Quality of care in FP services in Morocco. Studies in FP 26(3):154-168.

4. Bruce, J. 1990. Fundamental elements of the quality of care: A simple framework. Studies in FP 21(2):61-91.

5. Do, M.P., M.A. Koenig. 2007. Effect of FP services on modern contraceptive method continuation in Vietnam. J of Biosocial Sci 39(2):201-220.

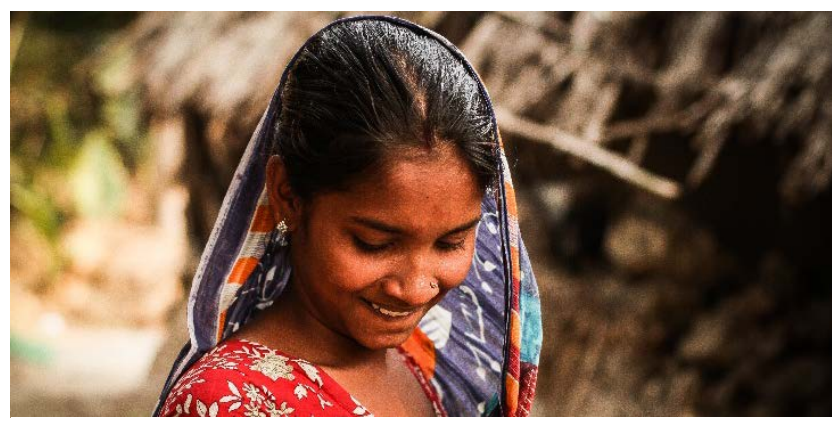

Photo Credit: Ashish Bajracharya

6. Gubhaju, B. 2009. Barriers to sustained use of contraception in Nepal: Quality of care, socioeconomic status, and method-related factors. Biodemography and Social Biol 55(1):52-70.

7. Hardee, K. et al. 2001. Quality of care in FP clinics in Jamaica. Do clients and providers agree? West Indian Med J 50(4):322-327.

8. Hong, R., L. Montana, V. Mishra. 2006. FP services quality as a determinant of use of IUD in Egypt. BMC Health Services Research 6:79-87.

9. Hull, V. 1996. Improving quality of care: Status report. FP. Population Briefs 2(3):6.

10. Huntington, D., S.R. Schuler. 1993. Simulated client method: Evaluating client-provider interactions in FP clinics. Studies in FP 24(3):187-193.

11. Jain, A.K., J. Bruce, B. Mensch. 1992. Setting standards of quality in FP programs. Studies in FP 23(6,1):392-395.

12. Jain, A.K., S. RamaRao, J. Kim, and M. Costello. 2012. Evaluation of an intervention to improve quality of care in a family planning program in the Philippines. J of Biosocial Science 44:27-41.

13. Ketting, E. 1994. Quality of care: Overview of major issues. Planned Parenthood Challenges 2:28-30.

14. Leon, F.R. et al. 2007. Challenging the courtesy bias interpretation of favorable clients' perceptions of FP delivery. Eval Review 31(1):24-42.

15. Madden, J.M. et al. 1997. Undercover careseekers: Simulated clients in the study of health provider behavior in developing countries. Social Sci and Medicine 45(10):1465-1482.

16. Maynard-Tucker, G. 1994. Indigenous perceptions and quality of care of FP services in Haiti. Health Policy and Planning 9(3):306317.

17. Mensch, B., M. Arends-Kuenning, A.K. Jain. 1996. Impact of the quality of FP services on contraceptive use in Peru. Studies in FP 27(2):59-75.

18. Mwaikambo, L. et al. 2011. What works in FP interventions: Systematic review. Studies in FP 42(2):67-82.

19. Naik, S., T. Suchi, R. Lundgren. 2010. Options for maintaining quality FP counseling: strategies for refresher training. Int'l J for Quality in Health Care 22(2):145-150.

20. Population Council. 1992. Quantitative assessment of the quality of care: Effects of provider training. Population Council INOPAL Updates. New York: Population Council.

21. RamaRao, S., M. Lacuesta, M. Costello, B. Pangolibay, and H. Jones. 2003. The Link Between Quality of Care and Contraceptive Use. Int'l FP Perspectives 29(2):76-83.

22. RamaRao, S., R. Mohanam. 2003. Quality of FP programs: Concepts, measurements, interventions and effects. Studies in FP 34(4):227-248.

23. Sanogo, D. et al. 2003. Improving quality of care and use of contraceptives in Senegal. African J of RH 7(2):57-73.

24. Sathar, Z., A.K. Jain, S. RamaRao, M. ul Haque, J. Kim. 2005. Introducing Client-Centered Reproductive Health Services in a Pakistani Setting. Studies in FP 36(3):221-234.

25. Schuler, S.R. et al. 1985. Barriers to effective FP in Nepal. Studies in FP 16(5):260-270.

26. Simmons, R., C. Elias. 1994. Study of client-provider interactions: Review of methodological issues. Studies in FP 25(1):1-17. 